\title{
Mottling on Sweet Cherry Fruit Is Caused by Exocarp Strain
}

\author{
Eckhard Grimm, Stefanie Peschel, and Moritz Knoche ${ }^{1}$ \\ Institute for Biological Production Systems, Fruit Science Section, Leibniz University Hannover, \\ Herrenhäuser Straße 2, 30419 Hannover, Germany
}

\begin{abstract}
AdDitional INDEX words. Prunus avium, anthocyanins, epidermis, hypodermis, skin, strain
Abstract. Mottling (pale spots) is clearly visible to the naked eye in all regions of the surface in all except for yellow cultivars of sweet cherry fruit (Prunus avium L.). The objective was to characterize these spots and their distribution on the exocarp. Within the spots, anthocyanins were limited to the epidermal cell layer but, in areas immediately adjacent to the spots, anthocyanins were present in the epidermal and in the hypodermal cell layers (making these areas darker). In 'Sam' sweet cherries, the median length and width of a spot in the cheek region were 390 and $162 \mu \mathrm{m}$, respectively, and the median area was $0.053 \mathrm{~mm}^{2}$ per spot. The spatial density in the cheek region averaged $1.94( \pm 0.13)$ spots per $\mathrm{mm}^{2}$ and the percentage of surface area covered by the spots was $12.5 \%( \pm 1.07 \%)$. Epidermal cells within a spot had slightly larger projected surface areas than those in the adjacent region and thicker cell walls. The margins of the spots did not align with the anticlinal walls of the epidermal cells. The spots' long axes were oriented parallel with the stem/stylar scar axis, whereas the slightly elongated epidermal cells within and adjacent to the spots were orientated perpendicular to the stem/stylar scar axis. The spatial density of spots and the cumulative spot area were highest in the region of the stylar scar, intermediate in the cheek and stem cavity, and lowest in the suture region. Spot spatial density on small fruit exceeded that on larger fruit, but the areas of individual spots was smaller. When an exocarp segment was excised from the cheek of a fruit, it contracted slightly as elastic strain was released. The projected surface area of the spots and that of the whole segment decreased to a similar extent. Our data suggest that spots result from a tensional failure during Stage III development in which the anthocyanin-containing hypodermal cell layer tears (schizogenously) and separates from the epidermis. This being the case, the pale spots (mottling) can be referred to as "strain spots."
\end{abstract}

Sweet cherry fruit growth follows a double sigmoid growth pattern, which is characterized by rapid increases of fruit mass and surface area during Stages I and III of development with much reduced expansion during the intermediate Stage II (Lilleland and Newsome, 1934; Tukey, 1934). In non-yellow cultivars, the color changes from green to yellow during Stage II and finally to red or black during early Stage III (Serrano et al., 2005). During Stage I, pericarp fruit growth occurs mostly by cell division. During Stage II the endocarp and the embryo develop, whereas cell expansion in the mesocarp accounts for most of the increase in fruit weight during Stage III development (Lilleland and Newsome, 1934; Tukey, 1934; Tukey and Young, 1939). The change in color is related to the degradation of chlorophyll, the presence of carotenoids in chromoplasts, and the accumulation of anthocyanins in the vacuoles (Serrano et al., 2005).

Recent investigations demonstrate that the exocarp is markedly strained during Stage III. First is because mature sweet cherry fruit gape when the fruit is cut longitudinally radially using a razor blade (Grimm et al., 2012). Second, exocarp segments decrease in area on excision from the fruit surface (Grimm et al., 2012). Third, the cuticular membrane is markedly strained during Stage III development (Knoche et al., 2004). Fourth, epidermal cells and microscopic cracks in the cuticle are highly oriented (Peschel and Knoche, 2005).

Received for publication 25 Sept. 2012. Accepted for publication 2 Nov. 2012. This research was funded in part by a grant from the Deutsche Forschungsgemeinschaft.

We thank Tobias Becker and Bishnu Prasad Khanal for technical assistance and Dr. S. Lang and Dr. N. Lownds for helpful comments on the manuscript. ${ }^{1}$ Corresponding author. E-mail: moritz.knoche@obst.uni-hannover.de.
Furthermore, the major axes of the somewhat elongated epidermal cells are oriented perpendicular to the microcracks, which is consistent with a cause-and-effect relationship. Fifth, the exocarp represents the outermost layer of approximately spherical fruit and is therefore subjected to the largest tension (Considine and Brown, 1981). Sixth, Measham et al. (2009) observed a positive relationship between tangential stress determined from the critical turgor pressure and the incidence of cracking.

In recent research we observed that the surface of red and black sweet cherries has a mottled appearance to the naked eye where the dark background color alternates with light, irregular pale spots up to $0.5 \mathrm{~mm}$ in length and/or width (S. Peschel and M. Knoche, unpublished data). These spots apparently decreased in number per unit fruit surface area and increased in length/width ratio from the stylar scar to the stem cavity region. Such a change would be consistent with an increasing rate of surface expansion from the stylar scar to the stem cavity region during Stage III development (Knoche et al., 2004). To our knowledge, there are no reports in the literature on the causes and significance of these pale spots. The purpose of this study was to characterize the pale spots and their distribution on the sweet cherry surface.

\section{Materials and Methods}

Plant material. Harvested mature sweet cherry fruit from cultivars that contained anthocyanins in the fruit skin were used throughout our study. This fruit comprised different batches of locally grown 'Sam' and 'Regina' sweet cherry fruit held in chilled atmosphere storage $\left(1.4{ }^{\circ} \mathrm{C}, 18 \% \mathrm{CO}_{2}, 17 \% \mathrm{O}_{2}\right)$ for up to 4 weeks and of off-season 'Sweetheart' and 'Lapins' fruit 
that were directly obtained from the importer. The conditions of production and those during transit and storage were usually unknown, but there were no signs of shriveling on the fruit, which appeared shiny. Moreover, the pedicels appeared always green, fresh, and fully turgid. It is judged likely that for commercial reasons (cherries are a very high-value fruit), the shipping/storage conditions were state of the art and the interval between harvest and sale had been minimized. Also, in previous seasons, we did not observe any change in the pattern, number, shape, or area of pale spots during storage (S. Peschel, unpublished data). All fruit used in experiments were selected for uniformity (based on color and size) within a given batch and for freedom from visual defects.

Preparation OF EXOCARP SEGMENTS FOR MORPHOMETRIC ANALYSIS. The exocarp of sweet cherry fruit is subjected to elastic strain and on excision of an exocarp segment (ES), this strain is released (Grimm et al., 2012). To maintain the elastic strain of an ES beyond excision, stainless steel washers $(6.4 \mathrm{~mm}$ inner diameter, $32.2 \mathrm{~mm}^{2}$ area) were mounted on the fruit surface using an ethyl-cyanacrylate adhesive (Loctite 406; Henkel Loctite Deutschland, München, Germany; Knoche and Peschel, 2006). After curing, the ES was excised by cutting tangentially through the fruit underneath the washer using a razor blade. When following this procedure, an ES was obtained (held inside the washer) where the elastic strain of the ES was substantially preserved. The ES so obtained comprised the cuticle, epidermis, hypodermis plus some adhering parenchyma.

ES with washers attached were transferred to the stage of a dissecting microscope (magnification $\times 1$ to $3.2, \mathrm{MZ10F}$; Leica Microsystems, Wetzlar, Germany) or a fluorescence microscope (magnification $\times 10$ to 40, BX-60; Olympus Europa, Hamburg, Germany). Digital micrographs were taken [Hitachi HV-C20 (Hitachi Denshi Europa, Rodgau, Germany) or DP 71 (Olympus Europa)] and processed using image analysis software (cell`P; Olympus Europa). Using this set-up, the following experiments were conducted.

The maximum lengths, widths, and areas of spots; distances between spots; and their orientations were determined in 'Sam' sweet cherry by image analysis. Aspect ratios were calculated as length/width on an individual spot basis. Distances between spots were indexed as the distances between the "centers of gravity" of adjacent spots. The frequency of pale spots was counted and their spatial density calculated on a surface area basis. Measurements of lengths, widths, areas, and distances were made on a total of 648 spots on 10 fruit. The orientation of spots ( $\mathrm{n}=40$ spots on 20 fruit) and of epidermal cells within and adjacent to the spots ( $n=400$ cells on 20 fruit) was determined as the angle of rotation between the longitudinal axis of the spot or cell and the stem/stylar scar axis of the fruit.

Cell size and cell wall thickness of cells within and outside the pale spots were quantified by image analysis using paired observations on 'Regina' sweet cherries. Cell size was indexed by the projected area of the cells calculated from the measured area of the pale spot and the number of cells within the spot ( $n=36$ spots on 20 fruit). The cell wall thickness $(n=200$ cells on 20 fruit) was indexed by the half thickness of the anticlinal cell wall separating two neighboring cells.

Potential changes in the dimensions and densities of spots with position on the fruit surface were studied in 'Sam' sweet cherry. Samples were taken adjacent to the stylar scar ("stylar scar"), halfway between the stylar scar and the equator ("cheek/stylar scar"), on the equator ("cheek"), and close to the rim of the stem cavity ("stem cavity"). Additionally, a position on the suture side in the equator ("suture") opposite to the cheek of the sweet cherry was investigated. Lengths, widths, areas, and aspect ratios were quantified on 20 spots per region and fruit and five fruit per region as described previously.

The effect of fruit size on spot characteristics in 'Sam' sweet cherry was investigated using small-sized [4 to $5 \mathrm{~g}$ (mean $4.6 \pm$ $0.1 \mathrm{~g})$ ] or medium-sized fruit [9 to $10 \mathrm{~g}$ (mean $9.5 \pm 0.1 \mathrm{~g})$ ]. Spot areas, numbers of epidermal cells per spot, and mean epidermal cell sizes within, and immediately adjacent to, spots were quantified on average 58 spots per fruit (range, 39 to 76 spots per fruit) and five fruit per size class as described previously.

RELEASE OF STRAIN FROM SPOTS AND EXOCARP SEGMENTS AFTER EXCISION. Elastic biaxial strain of spots was quantified using a modified strain-release assay (Grimm et al., 2012). A square pattern of four dots $\left[28.5 \pm 2.0 \mathrm{~mm}^{2}\right.$ (mean area $\pm \mathrm{SE}$ )] was applied to the surface of 'Lapins' sweet cherry in cheek $(n=23)$ and suture $(n=4)$ regions using a permanent marker. After drying, the dot pattern was photographed. Subsequently, an ES enclosing the dot pattern was excised using a razor blade (no stainless steel washer). The ES obtained was submerged in silicone oil [PAO 100 (Fuchs Europe Schmierstoffe Mannheim, Germany) or AK 5000 (Wacker Chemie, Munich, Germany)] for $24 \mathrm{~h}$ at ambient temperature to minimize water loss resulting from transpiration. The ES were transferred to the stage of the microscope and the dot pattern re-photographed. At this time the release of elastic strain from the excised ES had approached steady state (Grimm et al., 2012). The biaxial elastic strain was calculated using the following equation:

$$
\varepsilon^{E S}=\frac{A^{E S}-A_{0}^{E S}}{A_{0}^{E S}} \times 100
$$

where $\varepsilon^{E S}$ represents the fractional (percent) biaxial elastic strain, $A^{E S}$ (square millimeters) the area enclosed by the dot pattern on the fruit surface before excision, and $A_{0}^{E S}$ (square millimeters) $24 \mathrm{~h}$ after excision and the release of biaxial elastic strain. The biaxial elastic strain from individual spots $\left[\varepsilon^{\text {spot }}\right.$ (percent)] was calculated using this equation where $A^{\text {spot }}$ (square millimeters) and $A_{0}^{\text {spot }}$ (square millimeters) represent the projected areas of a spot before and $24 \mathrm{~h}$ after excision and release of elastic strain, respectively.

Terminology AND DATA ANALYSIS. The strain we refer to throughout this article is biaxial, reversible, and hence, the elastic area strain in the exocarp. Data were subjected to analysis of variance (Proc GLM) and regression analysis (Proc Reg) using SAS (Version 9.1.3; SAS Institute, Cary, NC). The significance level was set at $P<0.05$. The data in the figures and tables are presented as means and SEMS.

\section{Results and Discussion}

Pale spots were present on all regions of the surface of all anthocyanin-containing sweet cherry cultivars inspected (Fig. 1A). Pale spots were not detectable on the surface of yellow cultivars possibly because of a lack of contrasting pigmentation (M. Knoche, unpublished data). Thus, pale spots are not a unique property of a particular sweet cherry cultivar but are widespread, appearing in most commercial genotypes. 

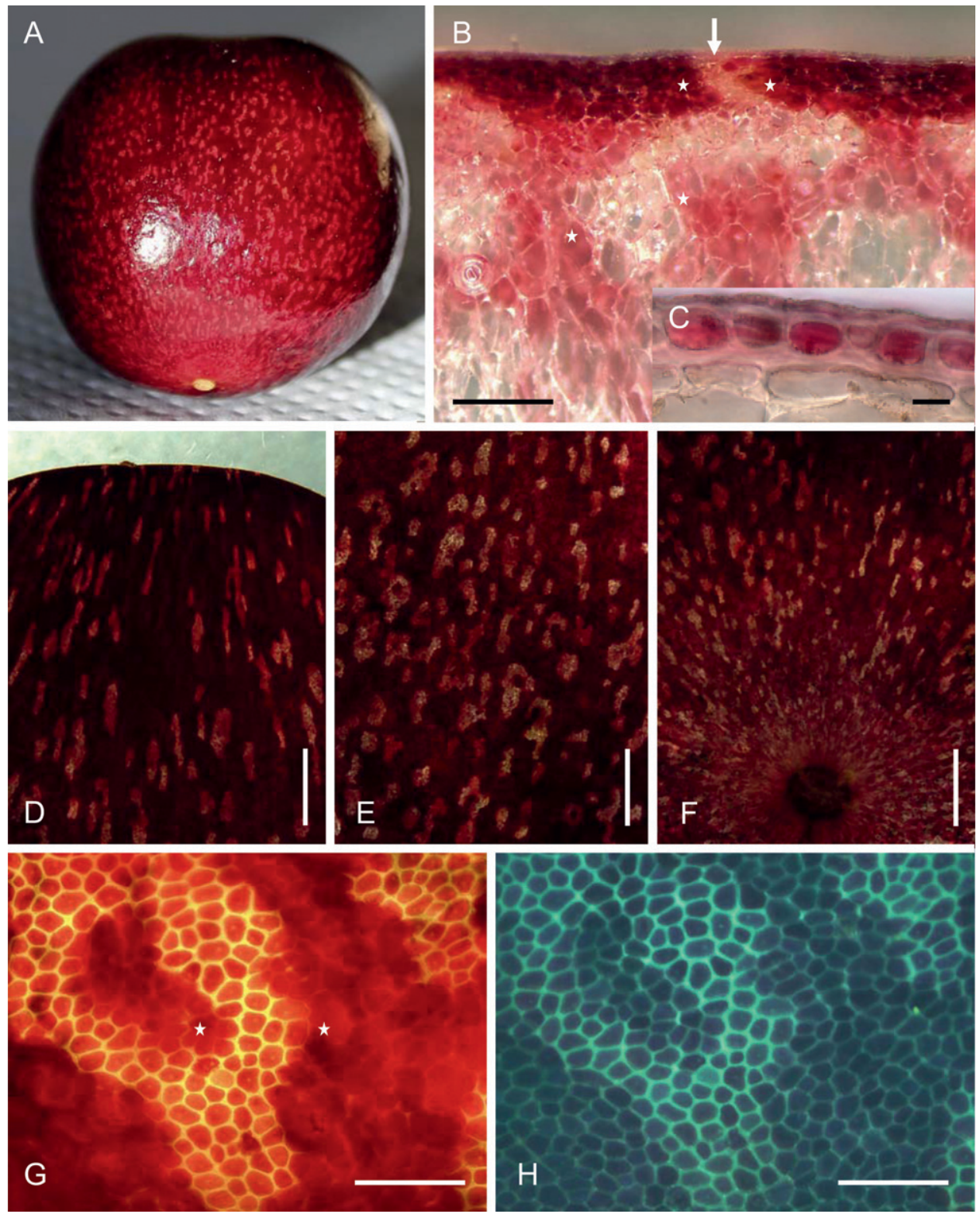

Fig. 1. Mottled appearance of 'Sweetheart' (A, B, D-F) and 'Sam' sweet cherry fruit surface $(\mathbf{C}, \mathbf{G}, \mathbf{H})$. (A) Overview of cheek and stylar scar regions. (B) Cross-section through fruit skin and underlying parenchyma in the cheek region when viewed in transmitted and incident white light. Arrow indicates pale spot. (C) Crosssection through the epidermis (with anthocyanins) and the first layer of hypodermal cells (without anthocyanins) within a pale spot viewed in transmitted white light. (D-F) Pattern of pale spots in the stem cavity (D), cheek (E), and stylar scar regions $(\mathbf{F})$ viewed in transmitted white light. $(\mathbf{G}-\mathbf{H})$ Top view of epidermis viewed in pale spot in transmitted white light $(\mathbf{G})$ and incident ultraviolet light $(\mathbf{H})$ showing autofluorescence. Bars: $0.5 \mathrm{~mm}(\mathbf{B})$, $0.02 \mathrm{~mm}(\mathbf{C}), 2 \mathrm{~mm}(\mathbf{D}-\mathbf{F}), 0.2 \mathrm{~mm}(\mathbf{G}-\mathbf{H})$. Asterisk indicates convex/concave margins of a pale spot.

In our study, cross-sections reveal that within the spots, the red color (anthocyanins) was limited to the vacuoles of the epidermis (Fig. 1B-C). In contrast, adjacent to the spots, anthocyanins were present in both the epidermal and hypodermal cells and, occasionally, in some deeper layers of the outer mesocarp (Fig. 1B).

The areas and shapes of the pale spots observed depended on the region of the fruit surface (Fig. 1D-F). A typical spot in the cheek region of 'Sam' sweet cherry had a median length and width of 390 and $162 \mu \mathrm{m}$, respectively (Fig. 2A) and, thus, was $\approx 2.4$ times longer than it was wide (Fig. 2B). A spot's median area was $0.053 \mathrm{~mm}^{2}$ (Fig. 2C). The distances between adjacent

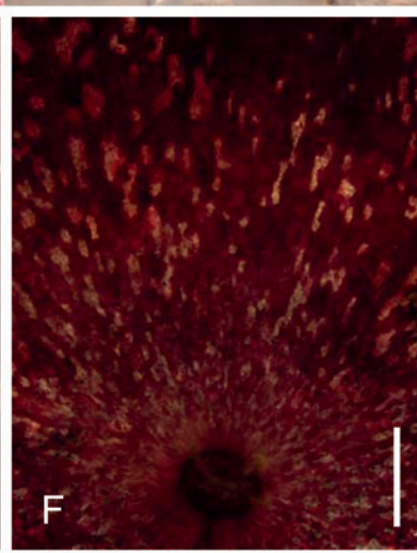

spots were regular as indicated by the relatively narrow frequency distribution of the spot:spot spatial separations that peaked at $510 \mu \mathrm{m}$ (Fig. 2D). The spatial density of spots in the cheek region averaged $1.94 \pm 0.13 \mathrm{~mm}^{2}$ and the percentage of fruit surface area covered by the spots was $12.5 \% \pm 1.1 \%$. The long axes of the spots were usually oriented parallel to the fruit's stem/ stylar scar axis, whereas the long axes of the epidermal cells were perpendicular to this (Fig. 3). There were no differences in the orientations of epidermal cells within or adjacent to a spot.

Epidermal cells within and outside of a spot were morphologically similar (Fig. 1G-H). However, within a spot, they had a slightly, but significantly, larger projected surface area $(+8.0 \%)$ and thicker cell walls $(+14.8 \%)$ as compared with the same values measured in areas adjacent to a spot (Table 1). The margins of a spot were not aligned with the anticlinal cell walls of the epidermal cells but instead often traversed the overlying epidermal cells. Within a spot, the opposing margins were often observed to run parallel to one another; in other words, if the spot margin was concave inward on one side, then it tended to be convex inward on the other (Figs. 1B and 1G).

The spatial density of spots differed between regions (Fig. 1G-H; Table 2). They were most frequent in the stylar scar region and decreased along the cheek toward the stem cavity (Fig. 1E-G). The lowest frequency of spots was observed on the suture side of the fruit. There were no spots on the suture line. There were no differences in spot area among regions. Spots in the stem cavity region were generally long and narrow with significantly higher aspect ratios than those in either the cheek or stylar scar regions (Table 2). Cumulative spot area was largest in the stylar scar region; intermediate in the cheek, the cheek/stylar scar, and the stem cavity region; and lowest in the suture region.

The spots were also affected by fruit size (Table 3). Spatial spot density on small fruit exceeded that on large fruit, but the areas of individual spots were smaller. There were no differences in the numbers of epidermal cells per spot, the percentages of the fruit surface area covered by spots, or the spot area per fruit (Table 3).

On excision of an ES from the cheek of a fruit (unsupported by a washer), the projected surface areas of the spots and that of 

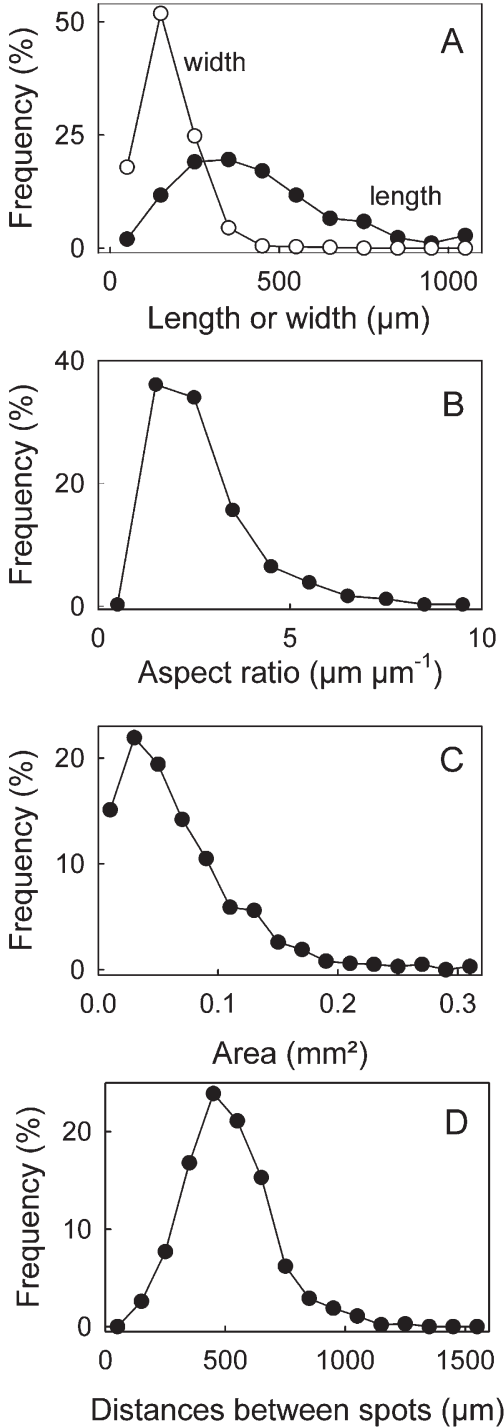

Fig. 2. Frequency distribution of lengths and widths (A), aspect ratios (B), areas of pale spot (C), and separation distances between adjacent spots on a mature 'Sam' sweet cherry fruit (D). Aspect ratios were calculated as length/width ratios of spots.

the exocarp segment both decreased (Fig. 4A). The areas of the spots before $\left(A^{\text {spot }}\right)$ and after excision $\left(A_{0}^{\text {spot }}\right)$ were positively and linearly correlated $\left[A^{\text {spot }}\right.$ (square millimeters) $=0.836$ $( \pm 0.004) \times A_{0}^{\text {spot }}$ (square millimeters) $\mathrm{n}=128, r^{2}=0.997$, $P<0.0001]$. Furthermore, the decrease in spot area $\left(\Delta A^{\text {spot }}\right)$ on excision was also positively and linearly related to $A^{\text {spot }}$ (Fig. 4A, inset). Performing the same calculation for the areas of exocarp segments before and after excision yielded a similar equation $\left[A^{E S}\right.$ (square millimeters) $=0.832( \pm 0.009) \times A_{0}^{E S}$ (square millimeters); $\left.\mathrm{n}=27, r^{2}=0.998, P<0.0001\right]$. Thus, the biaxial elastic strain from the spots and that from the ES were closely related $\left[\varepsilon^{\text {spot }}(\right.$ percent $)=5.66( \pm 1.02)+0.70( \pm 0.05) \times \varepsilon^{E S}$ (percent); $\mathrm{n}=27, r^{2}=0.897, P<0.0001$ (Fig. 4B)].

This study provides circumstantial evidence, which suggests that formation of pale spots is related to strain during Stage III development. First, in sweet cherry fruit, the spots are oriented parallel to the stylar scar/pedicel axis as are the microscopic cracks in the cuticle (Peschel and Knoche, 2005). Second,

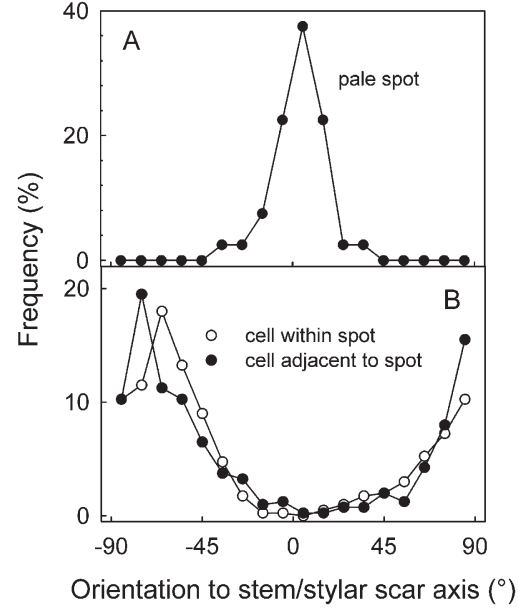

Fig. 3. Frequency distribution of relative orientations of pale spots (A) and of epidermal cells within or adjacent to these pale spots (B). The orientation of pale spots and of epidermal cells on the surface of 'Sam' sweet cherry was quantified as the angle of rotation between the stem/stylar scar axis of the fruit and the long axis of the pale spots or cells.

Table 1. Cell size and cell wall thickness of epidermal cells within and adjacent to the pale spots in the epidermis of mature 'Regina' sweet cherry fruit. ${ }^{2}$

\begin{tabular}{llcc}
\hline & & \multicolumn{2}{c}{ Epidermal cell } \\
\cline { 3 - 4 } Characteristic & Unit & Within spot & Adjacent to spot \\
\hline Cell size & $\mu \mathrm{m}^{2}$ & $1724 \pm 44 \mathrm{a}^{\mathrm{y}}$ & $1597 \pm 42 \mathrm{~b}$ \\
Cell wall thickness & $\mu \mathrm{m}$ & $6.2 \pm 0.1 \mathrm{a}$ & $5.4 \pm 0.1 \mathrm{~b}$
\end{tabular}

${ }^{\bar{z}}$ Cell size was indexed as the projected area of the cell and the cell wall thickness as the half thickness of anticlinal cell walls separating neighboring cells.

${ }^{y}$ Mean separation within rows by Tukey's Studentized range test at $P<0.05$.

epidermal cells within and adjacent to spots are oriented perpendicular to the longitudinal axes of the spots, which is also consistent with the orientations of epidermal cells underlying cuticular microcracks (Peschel and Knoche, 2005). Third, the length/width ratio of hypodermal cells in cherries is markedly greater than that of the overlying epidermal cells (Tukey and Young, 1939). This is consistent with the presence of significant strain, particularly in the hypodermis. Fourth, the marked increase in aspect ratio of the spots in the stem/cavity region is consistent with the substantially uniaxial distribution of strain in this region (Knoche et al., 2004; Peschel and Knoche, 2005). Fifth, there are no spots immediately above the suture. In this region, strain and hence, the release of elastic strain is impaired, probably by the relatively stiff suture tissues (Grimm et al., 2012). Sixth, opposing spot margins often reveal matching shapes (tessellation); it appears as if groups of hypodermal cells separated at some stage analogous to continental drift in the Earth's crust (Wegner, 1912). Finally, projected surface areas and cell walls of epidermal cells within spots were slightly larger $(+8 \%)$ and slightly thicker $(+15 \%)$, respectively, compared with those adjacent to the spots. This observation is also consistent with the strain hypothesis for spot formation. Strain caused failure in the hypodermal cell layers. As a result, the epidermal cell layer would be subjected to increased strain and stress resulting in larger projected areas 
Table 2. Characteristics of pale spots as affected by position on the surface of mature 'Sam' sweet cherry fruit $(n=5$ fruit $) .{ }^{\mathrm{z}}$

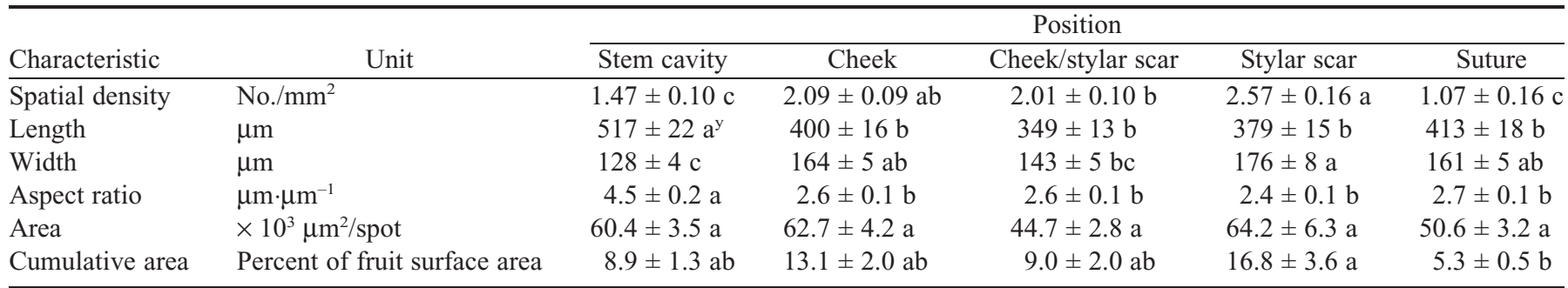

${ }^{\mathrm{z}}$ Aspect ratios were calculated as the length to width ratio of the spots.

y Mean separation within rows by Tukey's Studentized range test at $P<0.05$.

and increased cell wall deposition. Based on these arguments, we infer that the origin of exocarp spotting is strain-related, likely caused by the schizogenous separation of adjacent, anthocyanin-containing subepidermal and hypodermal cells during area expansion. Therefore, these spots can reasonably be termed "strain spots." They bear similarity to the human skin condition striae distensae, commonly known as pregnancy stretch marks (Elsaie et al., 2009).

The genesis of strain spots is not entirely clear and more detailed mechanisms are yet to be identified. First, strain spots may simply represent hypodermal cells that for genetic reasons lack anthocyanins (Fogle, 1958). Second, localized division of hypodermal cells lacking anthocyanin could result in the formation of spots if cell division continued to occur in the hypodermis during Stage III (daughter cells are usually similar to the parent cell from which they are derived, so if a parent cell lacks anthocyanin, so too will the daughter cells and vice versa). A similar phenomenon was reported by Considine and Knox (1979) for vacuolar tannins in the outer mesocarps of grape berries. Third, cell elongation in the hypodermis may be involved in the formation of strain spots. Fruit growth during Stage III is primarily by cell elongation and the high length/ width ratio of hypodermal cells in the sweet cherry hypodermis is indicative of strain and hence a driving force for cell elongation. Finally, a tangential separation of small "islands" of adjacent anthocyanin-containing hypodermal cells may have occurred allowing underlying, non-pigmented, subhypodermal cells to move upward toward the epidermis. This last possibility is not unrealistic, because the mesocarp is held under slight pressure by the strained exocarp (Considine and Brown, 1981) and tissue having viscoelastic properties will, over extended time scales, behave like a viscous fluid (Ranft et al., 2010). Morphometric data collected during the course of development are required to distinguish between these hypotheses. We are not aware of the existence of such data at this time.

From a mechanical point of view it would be interesting to know whether the lateral heterogeneity associated with strain spots of the exocarp facilitates localized failure and possibly fruit cracking when strained. Based on the small increase in projected areas of epidermal cells within a strain spot compared with those in adjacent areas, this appears unlikely, but definitive evidence is lacking.

\section{Conclusions}

This is the first report describing the mottled, or spotty, appearance of the skin of sweet cherry fruit. Circumstantial evidence suggests that these pale spots result from tensional
Table 3. Selected characteristics of pale spots on the cheek of small ( 4 to $5 \mathrm{~g}$ per fruit) and large (9 to $10 \mathrm{~g}$ per fruit) 'Sam' sweet cherry fruit.

\begin{tabular}{llcc}
\hline & & \multicolumn{2}{c}{ Fruit size class } \\
\cline { 3 - 4 } Characteristic & \multicolumn{1}{c}{ Unit } & Small & Large \\
\hline Spatial density & No. $/ \mathrm{mm}^{2}$ & $2.03 \pm 0.14 \mathrm{a}$ & $1.48 \pm 0.11 \mathrm{~b}$ \\
$\quad$ & & & \\
$\quad$ of spots & $\times 10^{3}{\mu \mathrm{m}^{2} / \mathrm{spot}}$ & $70.8 \pm 3.0 \mathrm{~b}^{\mathrm{z}}$ & $96.1 \pm 5.0 \mathrm{a}$ \\
Area & No./fruit & $2730 \pm 185 \mathrm{a}$ & $3213 \pm 243 \mathrm{a}$ \\
Spots per fruit & Percent of fruit & $14.1 \pm 1.9 \mathrm{a}$ & $13.9 \pm 2.4 \mathrm{a}$ \\
Cumulative & surface area & & \\
$\quad$ fractional area & & & \\
Epidermal cells & No./spot & $82.4 \pm 7.3 \mathrm{a}$ & $83.6 \pm 9.5 \mathrm{a}$
\end{tabular}

${ }^{\mathrm{z}}$ Mean separation within rows by Tukey's Studentized range test at $P<0.05$.
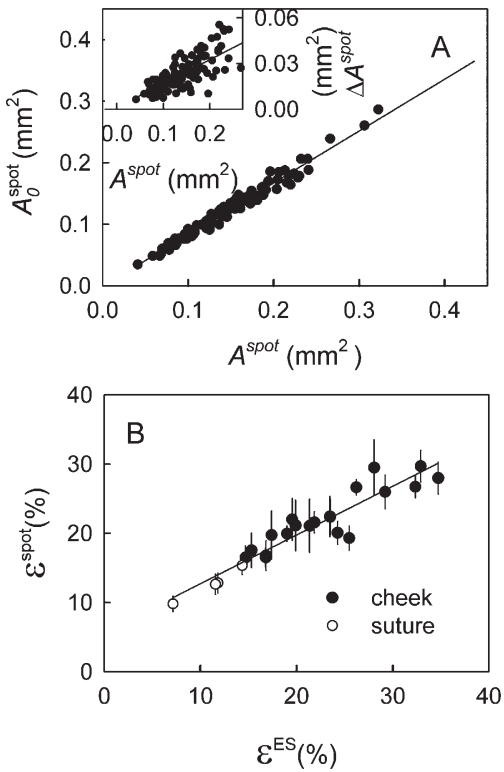

Fig. 4. (A) Relationship between the areas of pale spots on exocarp segments (ES) of 'Lapins' sweet cherry before $\left(A^{\text {spot }}\right)$ and after $\left(A_{0}^{\text {spot }}\right)$ excision of the ES. (Inset) Relationship between $A^{\text {spot }}$ and the change in area of the pale spots $\left(\Delta A^{\text {spot }}=A^{\text {spot }}-A_{0}^{\text {spot }}\right)$. Data points in $\mathbf{A}$ represent individual spots. (B) Relationship between the release of biaxial elastic strain from an ES $\left(\varepsilon^{E S}\right)$ and the release of biaxial elastic strain from the pale spots $\left(\mathcal{E}^{s p o t}\right)$ on the same ES. For quantifying $\varepsilon^{E S}$ four white dots were printed on the surface of the fruit, the area between the dots quantified before $\left(A^{E S}\right)$ and after excision and relaxation of an ES that contained the dot pattern $\left(A_{0}^{E S}\right)$. The $\varepsilon^{E S}$ was calculated as $\varepsilon^{E S}=\frac{A^{E S}-A_{0}^{E S}}{A^{E S}} \times 100$. Strain relaxation of the pale spots $\left(\varepsilon^{s p o t}\right)$ was quantified as $\varepsilon^{\text {spot }}=\frac{A^{\text {spot }}-A_{0}^{\text {spot }}}{A_{0}^{\text {poot }}} \times 100$. Data points represent individual ES with three to five pale spots measured per ES. 
forces in the exocarp that peak during Stage III. Therefore, we refer to the spots as "strain spots." Anatomically, strain spots result from groups of hypodermal cells that do not contain anthocyanins, whereas in neighboring areas, they do. The overlying epidermal cells all do contain anthocyanins. The detailed mechanistic basis for the non-uniform distribution of anthocyanins in the hypodermal layer and thus for the formation of strain spots is at present unknown. Further studies may identify whether the formation of strain spots is a mechanism involved in mitigating elastic strain in the exocarp thus, possibly, reducing catastrophic failure of the skin. If this were the case, it would be a useful adaptation. Finally, strain spots provide an interesting research tool for quantifying and comparing surface area expansion rates in different regions of a sweet cherry fruit.

\section{Literature Cited}

Considine, J. and K. Brown. 1981. Physical aspects of fruit growth-Theoretical analysis of distribution of surface growth forces in fruit in relation to cracking and splitting. Plant Physiol. 68:371-376.

Considine, J. and R.B. Knox. 1979. Development and histochemistry of the cells, cell walls, and cuticle of the dermal system of fruit of the grape, Vitis vinifera L. Protoplasma 99:347-365.

Elsaie, M.L., L.S. Baumann, and L.T. Elsaaiee. 2009. Striae distensae (stretch marks) and different modalities of therapy: An update. Dermatol. Surg. 35:563-573.

Fogle, H.W. 1958. Inheritance of fruit colour in sweet cherries (Prunus avium). J. Hered. 49:294-298.
Grimm, E., S. Peschel, T. Becker, and M. Knoche. 2012. Stress and strain in the sweet cherry skin. J. Amer. Soc. Hort. Sci. 137:383-390. Knoche, M., M. Beyer, S. Peschel, B. Oparlakov, and M.J. Bukovac. 2004. Changes in strain and deposition of cuticle in developing sweet cherry fruit. Physiol. Plant. 120:667-677.

Knoche, M. and S. Peschel. 2006. Water on the surface aggravates microscopic cracking of the sweet cherry fruit cuticle. J. Amer. Soc. Hort. Sci. 131:192-200.

Lilleland, O. and L. Newsome. 1934. A growth study of the cherry fruit. Proc. Amer. Soc. Hort. Sci. 32:291-299.

Measham, P.F., S.A. Bound, A.J. Gracie, and S.J. Wilson. 2009. Incidence and type of cracking in sweet cherry (Prunus avium L.) are affected by genotype and season. Crop Pasture Sci. 60:1002-1008.

Peschel, S. and M. Knoche. 2005. Characterization of microcracks in the cuticle of developing sweet cherry fruit. J. Amer. Soc. Hort. Sci. 130:487-495.

Ranft, J., M. Basan, J. Joanny, J.F. Elgeti, J. Prost, and F. Jülicher. 2010. Fluidization of tissues by cell division and apoptosis. Proc. Natl. Acad. Sci. USA 107:20863-20868.

Serrano, M., F. Guillen, D. Martinez-Romero, S. Castello, and D. Valero. 2005. Chemical constituents and antioxidant activity of sweet cherry at different ripening stages. J. Agr. Food Chem. 53:27412745.

Tukey, H.B. 1934. Growth of the embryo, seed, and pericarp of the sour cherry (Prunus cerasus) in relation to season of fruit ripening. Proc. Amer. Soc. Hort. Sci. 31:125-144.

Tukey, H.B. and J.O. Young. 1939. Histological study of the developing fruit of the sour cherry. Bot. Gaz. 100:723-749.

Wegner, A. 1912. Die Herausbildung der Großformen der Erdrinde (Kontinente und Ozeane), auf geophysikalischer Grundlage. Petermanns Geogr. Mitt. 63:185-195, 253-256, 305-309. 